\title{
TITLE:
}

\section{$<$ Note $>$ Snare Removal for Conservation of Chimpanzees in the Kalinzu Forest Reserve, Uganda}

\section{$\operatorname{AUTHOR}(S)$ :}

Hashimoto, Chie; Cox, Debby; Furuichi, Takeshi

\section{CITATION:}

Hashimoto, Chie ... [et al]. <Note> Snare Removal for Conservation of Chimpanzees in the Kalinzu Forest Reserve, Uganda. Pan Africa News 2007, 14(1): 8-11

ISSUE DATE:

2007-06

URL:

http://hdl.handle.net/2433/143473

RIGHT:

Copyright (C) Pan Africa News. 
$<$ NOTE $>$

Snare Removal for Conservation of Chimpanzees in the Kalinzu Forest Reserve, Uganda

Chie Hashimoto ${ }^{l}$, Debby Cox $^{2}$, Takeshi Furuichi ${ }^{3}$

1. Primate Research Institute, Kyoto University, Japan

2. Jane Goodall Institute Uganda

3. Faculty of International Studies, Meiji-Gakuin University, Japan 


\section{INTRODUCTION}

While hunting of primates, particularly chimpanzees, is not common in Uganda, hunting of other forest mammals, such as duikers and bushpigs is known to occur. This hunting has an indirect impact on chimpanzees and other primates as most of the hunting in Uganda is done by setting snares or jaw traps. As chimpanzees walk through the forest, their hands or feet may become trapped in the snare made of metal wire ${ }^{1}$. In two of the forests in Uganda (Kibale and Budongo), researchers have observed up to $25 \%$ of chimpanzees with snare-related injuries ${ }^{1,2,3}$. In the Kalinzu Forest, half of the adult males in the M group had snare injuries (Fig. 2) ${ }^{4}$.

In order to address such a critical situation, we started the snare removal program with the support of Disney Wildlife Conservation Fund, and continued the program with the support of Japan Ministry of Environment Global Environment Research Fund. We started recruiting and training staff in April 2005, and started the program from

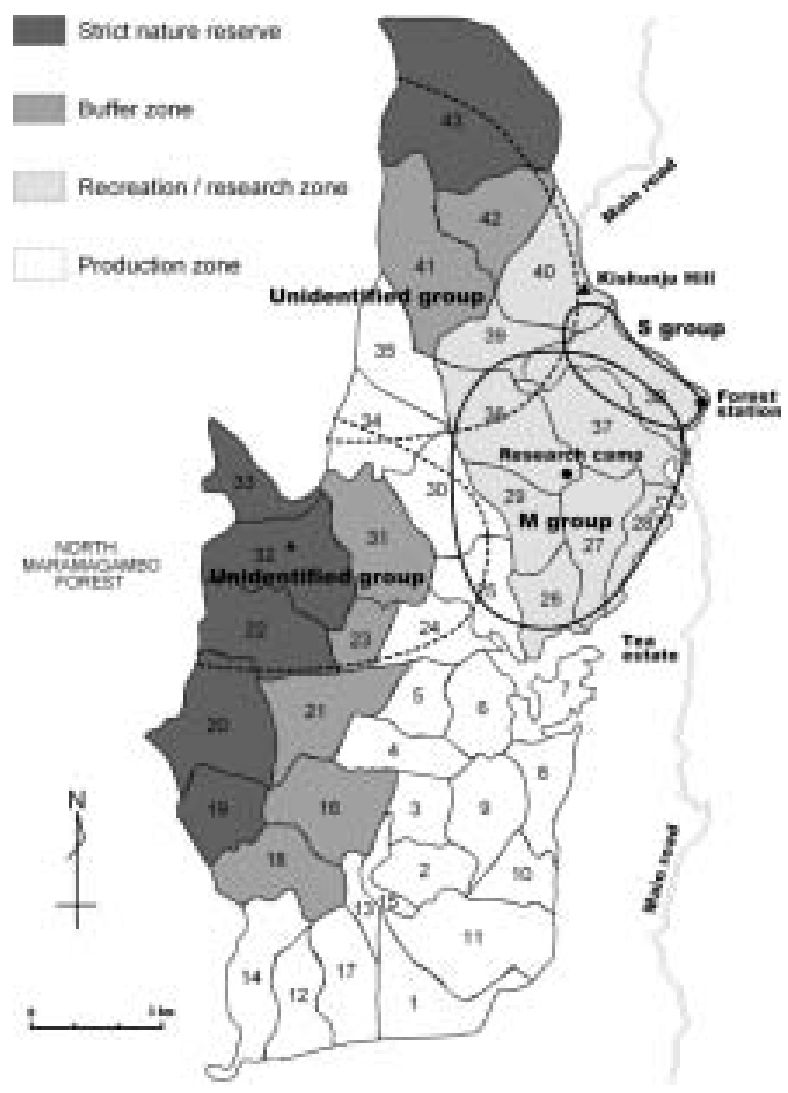

Fig. 1. Forest compartments and ranging areas of chimpanzee groups in the Kalinzu Forest Reserve.

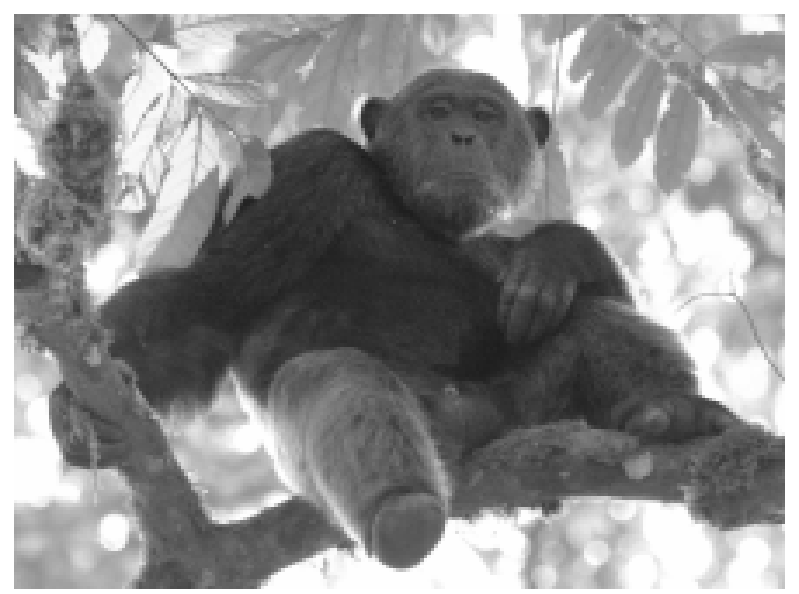

Fig. 2. An adult male who lost his foot by snare injury.

the beginning of May. Though we are still carrying out this program, here we report the results from May 2005 to June 2006.

\section{METHODS}

The Kalinzu Forest Reserve, which covers an area of $137 \mathrm{~km}^{2}$, is a part of Uganda's largest forest block where ecological survey of wild chimpanzees has been undertaken since $1992^{5}$. There inhabits at least four groups (communities) of chimpanzees (Fig. 1), with an estimated population of 230 individuals (1.67 chimpanzees per $\left.\mathrm{km}^{2}\right)^{6}$. The main study group, called the $\mathrm{M}$ group, comprising of 18 adult males, 24 adult females, and 26 immature individuals in January 2007.

We employed four persons to form two teams for the snare removal. Each consists of one ex-hunter who has a deep knowledge on the geography and technique for hunting in this area, and another person who graduated from primary school and is used to speaking and writing English. In order to raise local communities' awareness of this program, all persons were recruited from the villages adjacent to the Kalinzu Forest Reserve.

Kalinzu Forest Reserve consists of 43 compartments (Fig. 1). The northern area of the reserve is better conserved and has higher population of chimpanzees, monkeys and other animals. We have trail systems for research in the northeast: compartments 25 to 30 and 36 to 40. Two habituated groups of chimpanzees inhabit this area, 
and we mainly targeted the northern area in the snare removal program in this period.

The two teams patrolled different parts of this area from Monday to Saturday. When they found a lot of snares in some areas, they revisit these areas more intensively than others. It was difficult to cover compartments 43, 42 and 40 , due to lack of transportation for the teams. They walked through these compartments once a month from the northern edge of the reserve back to the main study area.

\section{RESULTS AND DISCUSSION}

From May 2005 to June 2006, we found and removed 1022 snares and 136 live traps (Table 1). There were two types of snares: one made of nylon strings and one made of metal wire. The former was mainly used for trapping guinea fowls, and the latter was used for trapping bushpigs and duikers and both are harmful to the chimpanzees $^{1,7}$.

Table 1. Number of snares found in the Kalinzu Forest Reserve.

\begin{tabular}{cccc}
\hline Year & Month & Snares & Live Traps \\
\hline 2005 & May & 71 & 6 \\
& Jun & 53 & 6 \\
& Jul & 77 & 0 \\
& Aug & 27 & 0 \\
& Sep & 54 & 14 \\
& Oct & 40 & 4 \\
& Nov & 59 & 27 \\
& Dec & 157 & 3 \\
& Jan & 98 & 6 \\
& Feb & 115 & 35 \\
& Mar & 152 & 24 \\
& Apr & 61 & 18 \\
& May & 105 & 11 \\
Total & Jun & 68 & 17 \\
\hline Total per month & & $\mathbf{1 1 3 7}$ & $\mathbf{1 7 1}$ \\
\hline
\end{tabular}

* Though the snare removal program supported by Animal Kingdom was terminated in April, the program is being continued by the Kalinzu Forest Project.

Among the areas where we made daily patrols, snares were frequently found in compartments $26,27,28$, and 40 that are close to villages and the tea estate. However, not so many snares were found in compartments 37 and 38 . Though we need to wait for further studies, we expect that the lower number of snares in these compartments is the results of our effort for conservation education and employment produced by the research and conservation activities in the villages adjacent to these compartments.

On the other hand, snares were most frequently found in compartment 40,42, and 43, though we visited there once a month. There are newly established villages to the north of the compartment 43 . Because those villages are located far from the main road, people living there are not well controlled by National Forestry Authority, governmental organization which is responsible for management of Ugandan Forest Reserves. In addition, those people have least opportunity to receive benefit from research, ecotourism, and conservation activities. How to control the illegal activities in this area remains the biggest problem for the conservation of chimpanzees in the Kalinzu Forest Reserve.

For one year since the beginning of the program, there had been no tendency of decrease in the number of snares removed. Although the slight increase might be a result of the increased skill in finding snares, we may need to continue this program for at least a few more years to evaluate its effect. Furthermore, we may need to develop conservation program, such as education program, at the villages adjacent to the compartments where snares were most frequently found.

Acknowledgments. We thank staff of the Jane Goodall Institute, the Kalinzu Forest Project, and the National Forestry Authority for technical support. This study was financially supported by the Disney Wildlife Conservation Fund and Japan Ministry of Environment Global Environment Research Fund (\#F-061 to T. Nishida).

\section{REFERENCES}

1. Waller JC, Reynolds V. 2001. Limb injuries resulting from snares and traps in chimpanzees (Pan troglodytes schweinfurthii) of the Budongo Forest, Uganda. Primates 42:135-139.

2. Edroma E, Rosen N, Miller P (eds) 1997. Conserving the Chimpanzees of Uganda: Population and Habitat Viability Analysis for Pan troglodytes schweinfurthii. IUCN/SSC Conservation Breeding Specialist Group, Apple Valley, MN.

3. Muller M 2000. Knuckle-Walking Wounded. Natural History 10/00:44-46.

4. Hashimoto C 1999. Snare injuries of chimpanzees in the Kalinzu Forest, Uganda. Pan Afr News 6:20-22.

5. Hashimoto C 1995. Population census of the Chimpanzees in the Kalinzu Forest, Uganda: Comparison Between Methods with Nest Counts. Primates 36:477-488. 
6. Plumptre AJ, Cox D 2006. Counting primates for conservation: primate surveys in Uganda. Primates 47:65-73.

7. Stokes EJ, Byrne RW 2006. Effect of snare injuries on the fig-feeding behavior of chimpanzees of the Budongo Forest,

Uganda: behavioral adaptations and long-term implications. In:

Primates of western Uganda, Newton-Fisher NE, Notman H,

Paterson JD Reynolds V (eds), New York: Springer, pp.281-297. 